\title{
MEMBANGUN SOLIDARITAS KEMANUSIAAN: KRITIK NABI AMOS TERHADAP PRAKTIK PELANGGARAN HAK ASASI MANUSIA
}

\author{
Gernaida K.R. Pakpahan ${ }^{1}$ ) \\ Sekolah Tinggi Teologi Bethel Indonesia ${ }^{1}$ \\ *)Email Correspondence:gernaida1967@gmail.com
}

Abstrac: $\quad$ This research aims to explore the implementation of human rights in the 8th century $B C$. The prophet Amos's criticism was aimed at the failure of nations to build human solidarity which was shown in various human rights violations. The approach method used is a form criticism approach, a synchronic and diachronic approach that seeks to examine the historical context of the book of Amos. The results obtained from the research show that violations of human rights during the Amos era include: deprivation of one's right to life and property, trafficking and human slavery, loss of fraternal solidarity, anger, and revenge, intimidation, terror and fear, the humiliation of human beings, refusal. rule of law. Israel's crimes against humanity are driven by a materialistic spirit so that it carries out the sale of the righteous, the poor, the weak, the exploitation of women, fines, and debts. Building humanitarianism through law enforcement so that truth and justice are created in society.

Keywords: Human rights, solidarity, crimes against humanity, justice, The Prophet Amos's.

Abstrak: $\quad$ Penelitian ini bertujuan untuk mengeksplorasi pelaksanaan hak azasi manusia pada abad ke 8 sM. Kritik nabi Amos ditujukan terhadap kegagalan bangsa-bangsa membangun solidaritas kemanusiaan yang ditunjukkan dalam berbagai pelanggaran hak asasi manusia. Metode pendekatan yang digunakan adalah pendekatan kritik bentuk, pendekatan sinkronik dan diakronik yang berusaha untuk mengkaji konteks historis kitab Amos. Hasil yang diperoleh dari penelitian bahwa pelanggaran terhadap hak asasi manusia pada zaman Amos meliputi: perampasan hak hidup dan hak milik seseorang, perdagangan dan perbudakan manusia, hilangnya solidaritas persaudaraan, kemarahan dan balas dendam, intimidasi, teror dan ketakutan, penghinaan terhadap diri manusia, menolak supremasi hukum. Kejahatan kemanusiaan Israel didorong spirit materialistik sehingga melakukan penjualan orang benar, orang miskin, orang lemah, eksploitasi perempuan, denda dan hutang. Membangun sodiraritas kemanusian melalui penegakan hukum sehingga tercipta kebenaran dan keadilan dalam masyarakat.

Kata kunci: Hak asasi manusia, solidaritas, kejahatan kemanusiaan, keadilan, Nabi Amos.

\section{PENDAHULUAN}

Manusia merupakan makhluk sosial yang akan selalu hidup berdampingan dan bergantung dengan sesamanya. Manusia dipanggil saling membangun dan memberdayakan agar ia mampu hidup harmonis dengan sesamanya. Fakta 
kehidupan mencatat penghargaan terhadap sesama manusia sering diabaikan. ${ }^{1}$ Pelanggaran hak-hak manusia dijumpai dalam praktik perbudakan, kerja paksa, perampasan hak milik, kejahatan seksual, perdagangan manusia, ${ }^{2}$ korban perang, pengungsian, diskriminasi ras, sosial politik, kemiskinan. ${ }^{3}$ Kejahatan terstruktur melalui keterlibatan lembaga kekuasaan, pemerintahan, lembaga hukum, bahkan lembaga keagamaan akan memperparah penderitaan manusia. ${ }^{4}$ Di dunia modern pun kaum perempuan, anak-anak dan orang miskin mudah dieksplotasi. Dengan dalih mendapatkan pekerjaan bagus dan pendapatan yang menjanjikan justru yang diperoleh sebaliknya yaitu upah yang rendah, perbudakan, kekerasan, menderita tekanan fisik dan psikologis. ${ }^{5}$ Kesadaran manusia untuk membangun kesamaan hak melalui solidaritas kemanusiaan cenderung merosot.

Kritik nabi Amos terhadap bangsa-bangsa memberi informasi penting keadaan abad ke-8 sM. Kejayaan Israel Utara dipimpin Yerobeam II dan kerajaan Yehuda dipimpin Uzia, digambarkan dalam kemakmuran ekonomi, ketentraman, keramaian pusat peribadatan. Berbeda dengan ungkapan keprihatian Amos yang memberi fakta hilangnya solidaritas persaudaraan, kemiskinan, penindasan, perbudakan, pelanggaran hukum dan hilangnya sikap etis manusia. ${ }^{6}$ Kecaman Amos terhadap Damsyik, Gaza, Tirus, Edom, Amon, Moab, Yehuda dan Israel dengan gaya kritiknya yang khas, "karena tiga perbuatan jahat bahkan empat, Aku

1 R. Honey, "Human Rights," in International Encyclopedia of Human Geography, 2009, https://doi.org/10.1016/B978-008044910-4.00785-9.

2 Tom Durbin and Jill St. George, "Human Traficking in Barbados: Achievements and Continuing Hurdles.," Journal of Eastern Caribbean Studies, 2013.

${ }^{3}$ Human Rights Watch, "World Report 2020: Events of 2019," Human Rights Watch, 2019.

${ }^{4}$ European Union Agency for Fundamental Rights, Violence against Women : An EU-Wide Survey, Publications Office of the European Union, 2014.

${ }^{5}$ Alexis A. Aronowitz, "Understanding Traficking in Human Beings: A Human Rights, Public Health, and Criminal Justice Issue," in International Crime and Justice, 2014, https://doi.org/10.1017/CCO9780511762116.018.

6 Will Kynes, "God, Justice, and Society: An Overview," Political Theology 14, no. 5 (2013): 589601, https://doi.org/10.1179/1462317X13Z.00000000037. 
tidak akan menarik keputusaKu" menunjukkan klimaksnya kejahatan setiap bangsa itu sehingga tidak dapat ditolerir lagi. ${ }^{7}$ Penindasan umumnya dilakukan para pemimpin dan bangsawan terhadap kaum miskin melalui kekuasaannya. Kemewahan hidup dinikmati segelintir orang melalui korupsi dan penguasaan milik masyarakat marjinal. ${ }^{8}$ Ketidakadilan sosial masyarakat menunjukkan kegagalan bangsa-bangsa memelihara kehidupan sosial yang sejahtera dan harmonis. Kemerosotan moral fakta memudarnya sikap etis dalam relasi sosial, sekaligus pula kemerosotan spiritual masyarakat. ${ }^{9}$

Agar pembahasan lebih fokus maka pertanyaan berikut akan dijadikan acuan: "Kejahatan apa saja yang dikecam Amos atas bangsa-bangsa? Bentuk pelanggaran hak asasi manusia seperti apa yang dilakukan bangsa-bangsa sehingga layak dihukum?” Untuk menemukan jawaban atas pertanyaan itu maka penelitian ini akan dikonsentrasikan pada pengeksplorasian kitab Amos khususnya Amos 1-2.

\section{METODE}

Pendekatan yang umum digunakan terhadap kitab Amos adalah kritik bentuk yang dilakukan Luther Mays ${ }^{10}$ dan Wolff. $^{11}$ Pendekatan ini memberi perhatian terhadap konteks yang lebih luas, namun secara keseluruhan memperhatikan unit-unit yang kecil dan sempit dalam teks atau tulisan, serta meneliti proses teks dari lisan hingga yang tertulis. Bertolak dari kritik bentuk

\footnotetext{
7 S.M Paul, Amos: A Commentary on The Book of Amos (Minneapolis: Fortress Press, 1991).

${ }^{8}$ Mark Rathbone, "Capitalism, the Book of Amos and Adam Smith: An Analysis of Corruption," HTS Teologiese Studies / Theological Studies 76, no. 4 (2020): 1-9, https://doi.org/10.4102/hts.v76i4.6194.

9 David A. Escobar, "Amos \& Postmodernity: A Contemporary Critical \& Reflective Perspective on the Interdependency of Ethics \& Spirituality in the Latino-Hispanic American Reality," Journal of Business Ethics, 2011, https://doi.org/10.1007/s10551-011-0841-x.

10 Luther Mays, Amos: The Old Testament Library (Philadelphia: Westminster Press, 1969).

${ }^{11}$ Hans Walter Wolff, Joel and Amos (Philadelphia: Fortress Press, 1997).
} 
maka pendekatan historis, seperti yang dilakukan John Hayes, ${ }^{12}$ memberi kesempatan untuk memposisikan kitab Amos sebagai kesatuan dari bagian-bagian khotbah yang luas ${ }^{13}$ dan menjadi alat yang tepat untuk mengeksplorasi kecaman Amos atas bangsa-bangsa. ${ }^{14}$ Melalui pendekatan sinkronik dan diakronik maka ucapan melawan bangsa-bangsa dalam Amos 1-2, akan tampak sebagai satu unit retorika, ${ }^{15}$ yang memiliki struktur, frase dan tema yang sama. ${ }^{16}$ Dengan demikian akan diperoleh informasi dan data yang komprehensif terhadap kitab itu.

\section{HASIL}

Nabi Amos menghendaki terciptanya keadilan sosial dalam masyarakat melalui perwujudan solidaritas kemanusiaan. Kegagalan membangun solidaritas kemanusiaan terlihat dalam praktik pelanggaran hak asasi manusia, misalnya perampasan hak hidup dan hak milik, perbudakan pelanggaran hak asasi manusia, pengabaian solidaritas persaudaraan, kemarahan, balas dendam, intimidasi, teror, ketakutan, penghinaan diri manusia, menolak supremasi hukum dan Kejahatan kemanusiaan. Hasil dari kajian Kitab Amos memberikan pemikiran untuk membangun kehidupan manusia dan menjaga hak asasi manusia. Perwujudan HAM dalam penelitian ini adalah menghentikan tindakan perbudakan kepada sesama manusia, menghentikan sistem politik yang tidak jujur, menghentikan peperangan dan membangun persaudaraan.

12 Kathryn Allan and Justyna A. Robinson, Current Methods in Historical Semantics, Current Methods in Historical Semantics, 2011, https://doi.org/10.1515/9783110252903.

${ }^{13}$ R. F. Melugin, "Amos in Recent Research," Currents in Research: Biblical Studies 6 (1986).

$14 \mathrm{~J}$. H. Hayes, Old Testament Theology: Its History and Development (London: SCM Press, 1985).

15 Karl Moller, A Prophet in Debate: The Rhetoric of Persuasion in the Book of Amos, Journal for the Study of the Old Testament Supplement Series, vol. 372, 2003.

${ }_{16}$ Carmen Klaussner and Carl Vogel, "A Diachronic Corpus for Literary Style Analysis," in LREC 2018 - 11th International Conference on Language Resources and Evaluation, 2019. 


\section{PEMBAHASAN}

Nabi $\operatorname{Amos}^{17}$ mendakwa delapan bangsa yaitu Damsyik, Gaza, Tirus, Edom, Amon, Moab, Yehuda dan Israel (Am. 1-2). Setiap dakwaan didasarkan atas tindak kejahatan bangsa itu dan hukuman yang akan diterimanya. Formula dakwaannya, "karena tiga perbuatan jahat bahkan empat" menunjukkan kualitas kejahatan bangsa itu. Kata פשע (pesa) 'kejahatan' adalah ungkapan politis לא אשיבנו: terhadap pemberontakan, persekutuan untuk melawan otoritas. ${ }^{18}$ Prasa (lo asivnu) "Aku tidak akan menarik kembali" memastikan keputusan Tuhan sudah final tidak dapat ditarik kembali. ${ }^{19}$ Runtuhnya solidaritas kemanusiaan nyata dalam pelanggaran hak-hak individu. ${ }^{20}$ Sorotan tajam Amos terhadap isu itu terlihat dalam uraian berikut.

\section{Perampasan Hak Hidup Dan Hak Milik (Am. 1: 3-5)}

Bangsa pertama yang didakwa Amos adalah Damsyik, ibu kota Aram. Tindakan brutal Damsyik, "oleh karena mereka telah mengirik Gilead dengan eretan pengirik dari besi." Gilead terletak di seberang Timur sungai Yordan, ${ }^{21}$ daerah perbukitan yang sangat subur untuk pertanian dan peternakan. ${ }^{22}$ Dataran Tinggi Golan sangat strategis sebagai benteng pertahanan terhadap musuh. ${ }^{23}$ Tindakan Damsyik "mengirik Gilead" sangat keji menyebabkan hak hidup manusia tercabut. Tradisi mengirik merupakan kebiasaan dalam masa panen

17 J Blenkinsopp, A History of Prophecy in Israel (London: Darton Longmann and Todd, 1996).

18 F.I Andersen and N Freedman, D, Amos (New Haven, CT : Yale University Press. The Anchor Yale Bible 24A, 2008).

19 James R Linville, "What Does ' It ' Mean? Interpretation at the Point of No Return in Re-Reading 'It ' This Paper Is a Synchronic Study of the Enigmatic Phrase ('I Will Not Cause ( Him / It ) to Return ') That Occurs in Each of the Eight Formally Linked Oracles against D," 2000, 400-425.

20 James Limburg, "Sevenfold Structures In The Book of Amos," Journal Biblical Literature 106/2 (1987): 217-22.

${ }^{21}$ K. A. Kitchen, "Gilead," in Ensiklopedi Alkitab Masa Kini (Yayasan Kasih Bina Komunikasi, 1994).

22 Wight Fred H., Manners and Customs of Bible Land (Chicago: Moody Press, 1980).

${ }^{23}$ N Hillyer, "Golan," in Ensiklopedia Alkitab Masa Kini (Yayasan Kasih Bina Kasih, 1994). 
gandum dan anggur. ${ }^{24}$ Menurut Fred H. Wight mengirik anggur dan gandum dengan cara memukuli bulirnya. Namun penggunaan alat pengirik biasanya dilengkapi dengan gerigi tajam yang berfungsi memotong dan pada ujungnya dibuat lubang saluran untuk mengalirkan hasil perasan ke dalam wadah palungan atau bak. ${ }^{25}$

Peristiwa pengirikan penduduk Gilead dikaitkan dengan kebijakan Hazael pada masa Yehu di Israel (2Raj. 10: 32-33). Kebrutalan Hazael terungkap dalam keluhan, "...terunanya akan kau bunuh dengan pedang, bayinya akan kau remukkan, dan perempuannya yang mengandung akan kau belah" (1Sam. 8: 18; bdg. 2Raj.15: 16; Hos. 14: 1). Penduduk Gilead disiksa, ditindas secara kejam dalam invasi Damsyik. Mereka diremukkan seperti biji gandum di atas papan pengirikan dari besi sehingga darah manusia ditumpahkan demi pemenuhan ambisi jahat Damsyik. Gilead menjadi ladang pembantaian, tubuh manusia diirik secara kejam tanpa peri kemanusiaan. Kejahatan sosiologis Damsyik telah merusak tatanan hidup manusia dengan merampas hak hidup seseorang. ${ }^{26}$ Melalui invasi militer tanah milik penduduk Gilead dirampas, penduduk dijual sebagai budak, kehidupan sangat mencekam dan menakutkan. ${ }^{27}$

Amos mengadukan kejahatan Damsyik ke penghakiman Allah. Akhirnya Damsyik menderita kekalahan perang, pemerintahannya diruntuhkan, penduduknya dibuang ke Kir. ${ }^{28}$ Kekalahan Hazael melawan Asyur di bawah

\footnotetext{
24 John F Walvoord and Roy B Zuck, The Bible Knowledge Commentary Old Testament, vol. 2, 1983.

25 Wight Fred H., Manners and Customs of Bible Land.

${ }^{26}$ McGee J. Vernon, Tru The Bible: Proverbs to Maleachi (Nashville: Thomas Nelson Publisher, 1982).

${ }^{27}$ R. Kessler, "The Crimes of the Nations in Amos 1-2," Acta Theologica 2018 (2018): 206-20, https://doi.org/10.18820/23099089/actat.Sup26.12.

${ }^{28}$ Fensham F. C., "Jahat, Kejahatan Dan Hukuman," in Ensiklopedia Alkitab Masa Kini (Yayasan Kasih Bina Kasih, 1994).
} 
pemerintahan Adad-nirari III $(811-783 \mathrm{sM}){ }^{29}$ Betapa penting mewujudkan keadilan sosial melalui penghargaan hak hidup seseorang dan jaminan perlindungan atas hak miliknya. Perlindungan hukum menjamin seseorang untuk menikmati kebebasan berkarya dan membangun relasi hidup harmonis dengan sesamanya.

\section{Perbudakan Pelanggaran Hak Asasi Manusia (6-8)}

Kecaman Amos terhadap Gaza, "oleh karena mereka telah mengangkut ke dalam pembuangan suatu bangsa seluruhnya, untuk diserahkan ke Edom." Gaza merupakan kota besar Filistin dan lalu lintas penting dalam perdagangan Mesir ke Asia Barat. Gaza dan Israel memiliki relasi pasang surut dalam politik, ekonomi, dan wilayah kekuasaan. Gaza merupakan batas selatan Kanaan (Kej. 10: 19), pernah direbut Yosua (Yos. 10: 41), diperdaya Simson (Hak. 16: 21-23), dan tabut perjanjian pernah dibawa ke Filistin (1Sam. 6: 7). ${ }^{30}$

Permainan politik kotor Gaza menjadikan bangsa lain budak. Penyerbuan Hazael ke Gilead dimanfaatkannya melakukan penyerangan dan pengangkutan penduduk ke Edom. Edom sebagai pusat pasar budak internasional tempat para tawanan perang diperjualbelikan. Komersialisasi budak-budak itu hanya menguntungkan para penguasa dan pengusaha. Mereka memperebutkan keuntungan dari penjualan budak, selanjutnya digiring ke Tirus untuk disebarkan berbagai bangsa di Timur Tengah. Ketidakberdayaan penduduk tertindas itu

29 John Bright, History of Israel (London: SCM Press, 1960).

30 Mitchell T. C; A.R Millard., "Gaza," in Ensiklopedia Alkitab Masa Kini (Yayasan Kasih Bina Kasih, 1994). 
menjadi objek kesenangan Gaza. Donald R. Sunukjian menganggap komersialisasi di pasar budak adalah kejahatan kemanusiaan. ${ }^{31}$

Pengangkutan penduduk Gilead baik laki-laki, perempuan dan anak-anak sebagai budak menyebabkan Gaza dituntut ke penghakiman Allah. Akibatnya, Filistin kehilangan Asdod karena "penduduknya dilenyapkan." Asdod kota pelabuhan besar, lalu lintas berbagai jenis kapal, kilang minyak besar, serta pusat pangkalan militer. ${ }^{32}$ Asdod dihancurkan Sargon II sekitar tahun 711 sM. Kehancuran Askelon karena "pemegang tongkat kerajaannya" yakni para suksesor kerajaan, penguasa dan kaum bangsawan ditaklukkan. ${ }^{33}$ Tiglat Pileser II menaklukkan Askelon sekitar 734 sM. Kota Ekron pemukiman terbesar pada zaman besi, daerah pengrajin tanah liat juga dihukum Tuhan. ${ }^{34}$ Ekron ditaklukkan Asyur sekitar 705 sM. $^{35}$ Perdagangan dan perbudakan manusia melanggar hak hidup manusia dan harus menerima konsekuensi hukuman Tuhan.

\section{Pengabaian Solidaritas Persaudaraan (9-10)}

Tirus didakwa Amos karena "mereka telah menyerahkan tertawan suatu bangsa seluruhnya kepada Edom" dan "tidak mengingat perjanjian persaudaraan." Tirus merupakan kota pelabuhan sangat kaya karena pendapatannya melimpah dari transasksi perdagangan. ${ }^{36}$ Menurut Keil dan Delitsch, meletusnya perang Aram menjadi kesempatan bagi Hazael dan Benhadad memperluas wilayah kekuasaannya. Tirus memakai kesempatan itu untuk menyerahkan para budak ke

${ }^{31}$ Donald R Sunukjian, "Amos," in The Bible Knowledge Commentary Old Testament, ed. John F Walvoord and Roy B Zuck (Victor Books, 1985).

32 D. J. Wiseman, "Asdod," in Ensiklopedi Alkitab Masa Kini (Yayasan Kasih Bina Kasih, 1994).

${ }^{33}$ D. J. Wiseman, "Askelon," in Ensiklopedi Alkitab Masa Kini (Yayasan Kasih Bina Kasih, 1994).

${ }^{34}$ T. C. Mitchell, "Ekron," in Ensiklopedi Alkitab Masa Kini (Yayasan Kasih Bina Kasih, 1994).

35 Kessler, "The Crimes of the Nations in Amos 1-2."

${ }^{36}$ Mays, Amos: The Old Testament Library. 
Edom untuk dijual. ${ }^{37}$ Tirus aktif terlibat melakukan perdagangan dan perbudakan manusia dengan mengabaikan solidaritas persaudaraan. ${ }^{38}$ Pada zaman Daud dan Salomo, Tirus dan Israel telah mengikat perjanjian (1Sam. 5: 11; 1Raj. 5: 18), untuk saling menguntungkan di bidang ekonomi dan sosial politik.

Hubungan bilateral itu rusak karena Tirus "tidak mengingat perjanjian persaudaraan." Kata זכר (zakar) "mengingat" istilah teknis dalam terminologi politik Mesopotamia. Menurut S. M. Paul, kejahatan Tirus bukanlah sekedar melupakan perjanjian persaudaraan, melainkan tindakan tak bermoralnya sebagai lalu lintas perdagangan budak. ${ }^{39}$ Komersialisasi budak merupakan pengingkaran ikatan perjanjian, sekaligus sebagai penolakan terhadap otoritas Tuhan. ${ }^{40}$ Penjualan budak menjadi komoditi penting dalam pembangunan ekonomi saat itu. Motivasi mendulang keberuntungan melalui perdagangan dan perbudakan manusia menyebabkan terpuruknya solidaritas persaudaraan. Untuk itulah Amos mendakwa Tirus untuk mempertanggungjawabkan perbuatannya di pengadilan Allah.

\section{Kemarahan dan Balas Dendam (11-12)}

Sejak awal hubungan Edom dan Israel sering kurang harmonis. ${ }^{41}$ Konflik kedua bangsa bersaudara itu dilatarbelakangi persaingan, kebencian dan dendam. ${ }^{42}$ Kecaman Amos, "oleh karena ia mengejar saudaranya dengan pedang, dan mengekang belas kasihnya, memendam amarahnya untuk selamanya dan

${ }^{37}$ Keil F dan Delitzsch, Commentary on the Old Testament: Minor Prophets (Peabody: Hendrickson Publisher, 1989).

38 Durbin and St. George, "Human Traficking in Barbados: Achievements and Continuing Hurdles."

39 Paul, Amos: A Commentary on The Book of Amos.

40 J. W. L. Hoad, "Janji," in Ensiklopedi Alkitab Masa Kini (Yayasan Komunikasi Bina Kasih, 1994).

41 Juan Manuel Tebes, "Memories of Humiliation, Cultures of Resentment towards Edom and the Formation of Ancient Jewish National Identity," Nations and Nationalism 25, no. 1 (2019): 124-45, https://doi.org/10.1111/nana.12367. 1994).

42 J. A. Thompson, "Edom," in Ensiklopedi Alkitab Masa Kini (Yayasan Komunikasi Bina Kasih, 


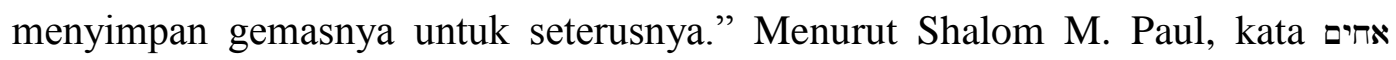
(akhim) menggambarkan hubungan persaudaraan dan diplomatik antara Israel dengan Edom. Ikatan perjanjian כרת ברית (karat berit) keduanya telah lama terjalin (Kej. 27: 40), namun penggunaan kata pedang mengindikasikan adanya pertentangan dan perlawanan antara keduanya. ${ }^{43}$ Sikap Edom yang "mengekang belas kasihnya" ושישת רחמיו (wetsakhat) (rakhammain) telah merusak tali persaudaraan keduanya. ${ }^{44}$ Kata רחם (rakham) merupakan perwujudan kasih dari yang superior membantu yang inferior. ${ }^{45}$ Dalam superioritasnya Edom menyimpan amarah dan dendamnya melalui persekongkolan dengan bangsabangsa untuk kejatuhan Israel. Edom terlibat rekayasa yang menyebabkan Israel terbuang dari tanah miliknya. Ia bersukacita atas kemalangan Israel ketika ditawan ke pembuangan (Ob. 1: 12-14; Mzm. 137: 7). ${ }^{46}$ Rekayasa politik jahat akibat dendam menghilangkan solidaritas persaudaraan. Edom dibawa ke penghakiman Allah dan dihukum melalui kekalahan perang. Edom ditaklukkan Asyur pada abad ke-8 sM, kemudian diambil alih Nabate suku Arab sekitar tahun 400-300 sM. ${ }^{47}$

\section{Intimidasi, Teror, Ketakutan (13-15)}

Manusia harus bebas dari intimidasi, teror dan ketakutan. Amon dikecam "oleh karena mereka membelah perut perempuan-perempuan hamil di Gilead dengan maksud meluaskan wilayahnya." Bangsa Amon ('ammon) keturunan BenAmi, putra Lot memiliki persaudaraan dengan Israel (Kej. 19: 38). Masalah

\footnotetext{
${ }^{43}$ Bob Becking, "The Betrayal of Edom: Remarks on a Claimed Tradition," HTS Teologiese Studies / Theological Studies 72, no. 4 (2016): 1-5, https://doi.org/10.4102/hts.v72i4.3286.

${ }^{44}$ Keil F dan Delitzsch, Commentary on the Old Testament: Minor Prophets.

45 Lawrence O. Richards, Expository Dictionary of Bible Words (Grand Rapids: Zondervan Publishing House, 1985).

46 James D. Nogalski and John Barton, "Joel and Obadiah: A Commentary," Journal of the American Oriental Society, 2003, https://doi.org/10.2307/3217894.

47 John F Walvoord and Roy B Zuck, The Bible Knowledge Commentary (Voctor Books, 1985), https://doi.org/10.2307/3263215.
} 
wilayah perbatasan menyebabkan ketegangan antar bangsa (Ul. 12: 19). ${ }^{48}$ Demi perluasan wilayah, Amon melakukan intimidasi dan teror melalui tindakan sadis yakni membelah perut perempuan hamil. Penyerbuan Aram ke Gilead dimanfaatkan Amon melakukan tindakan brutal terhadap perempuan dan bayi dalam kandungannya. Para perempuan diperdaya dan janin dalam kandungannya dibunuh. $^{49}$ Tindakan biadab itu adalah penghinaan yang mencabut hak hidup perempuan dan bayinya (Hak. 11; 1Sam 11: 1-2; 2Sam 10: 1,2; 2 Taw. 20). Amos membawa Amon ke penghakiman Allah atas tindakannya merampas hak hidup perempuan hamil. Akibatnya, Amon menderita kehancuran karena kekalahan perang, para pemimpin dan pembesarnya ditawan ke pembuangan. ${ }^{50}$ Amon ditaklukkan Tiglat Pileser III dari Asyur sekitar 734 sM. ${ }^{51}$

\section{Penghinaan Diri Manusia (Amos 2: 1-3)}

Prinsip keadilan sosial dinyatakan dalam penghargaan terhadap diri manusia termasuk sikap terhadap orang yang sudah meninggal. Amos mengecam tindakan Moab "membakar tulang-tulang raja Edom dan menjadikannya kapur." Moab adalah keturunan Lot dan berdiam di sebelah Timur Laut Mati. Bangsa itu telah maju di bidang agaria, bangunan dan seni serta kotanya memiliki pertahanan yang kuat. Pertambahan jumlah penduduk mendorongnya melakukan ekspansi wilayah kekuasaan yang memicu perselisihan dengan Israel. ${ }^{52}$ Ketegangan Israel dengan Moab tercipta sejak Israel keluar dari Mesir, kebencian Balak (Bil. 22-24)

\footnotetext{
48 K. A. Kitchen, "Bani Amon" (Yayasan Komunikasi Bina Kasih, 1994).

49 To Samuel and Noah Kramer, "' Ripping Open Pregnant Women " in Light of an Assyrian Analogue Author ( $\mathrm{s}$ ): Mordechai Cogan Published by : American Oriental Society American Oriental Society Is Collaborating with JSTOR to Digitize , Preserve and Extend Access to Journal Of" 103, no. 4 (2014): 75557.

50 Keil F dan Delitzsch, Commentary on the Old Testament: Minor Prophets.

51 Walvoord and Zuck, The Bible Knowledge Commentary.

52 J. A.; Thompson and A. R. Millard, "Moab," in Ensiklopedi Alkitab Masa Kini (Yayasan Komunikasi Bina Kasih, 1996).
} 
dan invasi Eglon ke Israel melalui penindasan (Hak. 3: 12-30). Tindakan Moab membakar tulang-tulang raja Edom adalah tindakan memalukan dan tidak terpuji. Bangsa-bangsa di Timur Tengah menolak pembakaran mayat, sebab mereka meyakini pembakaran mayat akan menghalangi jiwa orang mati beristirahat di tempat pekuburan dan dibiarkan mengembara. ${ }^{53}$ Perbuatan Moab itu adalah sikap yang memandang rendah kemanusiaan seseorang. Sikap tidak hormat terhadap orang mati merupakan respon terhadap orang hidup. Raja atau pemimpin layak dihormati termasuk pada waktu mereka sudah mati.

Setiap individu patut dihormati sebagai manusia yang utuh. Menghina individu juga penghinaan terhadap kemanusiaan seseorang. Amos mendakwa Moab di pengadilan Allah, bangsa itu "tenggelam dalam kegaduhan" dan "sorak sorai pada waktu sangkakala berbunyi." Hal itu bukanlah suka cita kemenangan perang dengan hadiah jarahan dan tawanan. Peniupan sangkakala memanggil Moab ke medan pertempuan. Akibat keganasan perang, Moab menderita kekalahan parah. Para pembesar dan penduduknya ditawan musuh. Kejahatan Moab dibalas dengan kejatuhannya untuk menyatakan keadilan Allah terhadap kemanusiaan.

\section{Menolak Supremasi Hukum (4-5)}

Selain dakwaan atas kejahatan bangsa-bangsa, Yehuda dan Israel pun tidak luput dari kecaman Amos. Yehuda dikecam karena "menolak hukum TUHAN dan tidak berpegang pada ketetapan-ketetapanNya." Pemulihan hak asasi Israel dinyatakan dalam pembebasannya dari perbudakan Mesir, dituntun di

${ }^{53}$ BJ Boland, Tafsiran Kitab Amos (Jakarta: BPK Gunung Mulia, 1993). 
padang gurun, diberikan hukum Taurat tanah perjanjian. ${ }^{54}$ Pendengar nubuat Amos mengerti pemberitaannya. ${ }^{55}$ Kecamannya terhadap sosio-ekonomi kalangan masyarakat yang memperoleh kemakmuran yang bertentangan dengan hukum Tuhan. ${ }^{56}$ Keangkuhan Yehuda tampak dalam penolakannya terhadap "hukum Tuhan." מאס Ka'as) "menolak" hukum atau ajaran Tuhan untuk membela kebenaran dan keadilan. Menurut Andersen dan Freedman "hukum TUHAN" adalah "firman TUHAN," "perintah," "tradisi imam-imam," "ketetapan," yang berfungsi sebagai petunjuk hidup Israel. ${ }^{58}$ VanGemeren dan William menganggap tujuan hukum itu agar umat hidup sesuai dengan kehendak Tuhan. ${ }^{59}$ Mendenhall menghubungkan hukum Taurat itu dengan naskah perjanjian. ${ }^{60}$ Artinya, hukum Tuhan adalah ajaran Tuhan agar umat hidup sesuai dengan perjanjian yang diikatNya dengan Israel. ${ }^{61}$

Kegagalan Yehuda memelihara hukum Tuhan karena mengikuti ”dewa kebohongan" (Am. 2: 4). ${ }^{62}$ Kata (kzv) "dewa-dewa kebohongan" menunjuk ilah-ilah atau berhala ciptaan manusia. Dalam hukum ibadah Israel, berhala adalah musuh dan kekejian bagi Allah. Yehuda mengikuti penyembahan berhala nenek moyangnya. Kata הלך (halakh) menunjukkan kesetiaan Yehuda mengikuti

54 Gerhard von Rad, Theology of the Old Testament (New York: Harper and Row, 1960).

${ }^{55}$ Christoph Barth, Teologi Perjanjian Lama (Jakarta: BPK Gunung Mulia, 1993).

${ }^{56}$ Mays, Amos: The Old Testament Library. York, 1978).

57 De Waard, W Jan Smalley, and Illiam A, A Translator's Handbook on The Book of Amos (New

58 Andrerson and Freedman, Amos: A New Translation with Introduction and Commentary (New York: The Anchor Bible, Doubleday, 1989).

59 William VanGemeren and William, "Biblical Concept of Law," in Baker Encyclopedia of the Bible (Grand Rapids: Baker Book House, 1989).

60 G. E. Mendenhall, Law and Covenant in Israel and Ancient Near East (Pittsburgh: The Biblical Colloquium, 1955). 1982).

${ }^{61}$ Rousas John Rushdaony, Law and Society: Institut of Biblical Law (Vallecito: Ross House Books,

62 Gary V. Smith, Amos: A Commentary (Grand Rapids: Zondervan Publishing House, 1989). 
"keyakinan nenek moyangnya" itu. ${ }^{63}$ Menurut Gary Smith, "nenek moyang Israel" adalah nabi palsu atau pemimpin palsu yang membawa kesesatan dalam hidup keagamaan. Terbukti penyembahan berhala mempengaruhi kemerosotan moral, kehidupan masyarakat sipil dan perayaan agamani. Mark Rathbone melihat lunturnya keyakinan terhadap Allah menyebabkan kemerosotan dalam penghargaan kesetaraan manusia, sebagai akibat kegagalan manaati Taurat. $^{64}$ Faktanya dalam kehidupan sosial terjadi penindasan dan eksploitasi terhadap orang lemah. Amos menyerukan penegakan keadilan sosial untuk membela masyarakat kecil dengan membangun sosidaritas persaudaraan. Sekalipun datangnya keadilan itu melalui jalan panjang yakni hukuman Allah. Yehuda menderita kekalahan perang, ${ }^{65}$ dan takluk pada kekuasaan Babel tahun 586 sM.

\section{Kejahatan Kemanusiaan (6-8)}

Klimaks kecaman Amos atas bangsa-bangsa dinyatakan dalam dakwaannya terhadap Israel. Dalam rumusan dakwaan itu diperlihatkan semakin memuncaknya kejahatan kemanusiaan, ${ }^{66}$ yang diidentifikasi sebagai berikut:

\section{Spirit materialistik (6)}

Penindasan Israel terhadap sesamanya didorong sifat materialistik. ${ }^{67}$ Israel "menjual orang benar karena uang dan orang miskin oleh karena sepasang kasut." Penyebutan "orang benar" צדיק (tsadiq) menunjuk pelaksanaan hukum di

\footnotetext{
63 Paul, Amos: A Commentary on The Book of Amos.

${ }^{64}$ Rathbone, "Capitalism, the Book of Amos and Adam Smith: An Analysis of Corruption."

65 James Alfred Loader, "Understanding of Failure and Failure of Understanding: Aspects of Failure in the Old Testament," HTS Teologiese Studies / Theological Studies 70, no. 1 (2014): 1-12, https://doi.org/10.4102/hts.v70i1.2657. 105 (1986).

${ }^{66}$ Aejmelaeus, "A Function and Interpretation of Ki in Biblical Hebrew," Journal Biblical Literature

${ }_{67}$ Gerhard F. Hasel, Understanding the Book of Amos: Basic Issues in Current Interpretation (Grand Rapids: Baker Book House, 1999).
} 
lembaga pengadilan raja. ${ }^{68}$ Kata tsadiq juga menunjuk umat yang dibenarkan Tuhan. ${ }^{69}$ Motif menjual orang benar adalah uang. Sikap materialisme mendorong timbulnya nafsu jahat untuk menguasai orang lain termasuk menjual orang benar. Kaum kapitalis itu memperjualbelikan kebenaran demi uang. Menurut Smith, "menjual orang benar karena uang" merupakan bentuk ketidakadilan dan pelanggaran terhadap hak hidup seseorang. ${ }^{70}$ Sementara "orang benar" adalah orang miskin yang tidak mampu membayar hutangnya kepada para kreditor. Ketamakan para kreditor semakin nyata dengan menjadikan orang miskin sebagai budak. Para tuan atau orang kaya memperdaya orang miskin di pengadilan melalui penyogokan hakim. Para hakim memenangkan perkara masyarakat karena disuap sehingga orang miskin makin tertindas. Tindak koruptif para pemimpin yang berkuasa memperlihatkan kemerosotan moral dan ekonomi. Hal itu tampak dalam tindakan menjual orang benar, orang miskin, orang lemah, dan orang sengsara karena materi. Hukum pada hakikatnya bukanlah sekedar perintah moral melainkan prinsip dan pondasi bagi struktur kemasyarakatan. ${ }^{71}$

\section{Menjual orang miskin (6)}

Pudarnya rasa kemanusiaan Israel dinyatakan dalam tindakanya "menjual orang miskin karena sepasang kasut.” Kata אביון (eviyon) menunjuk orang miskin yang sama sekali tidak memiliki apa-apa. Sementara sepasang kasut memperlihatkan milik orang miskin yang tidak bernilai tinggi. Dalam hukum Musa "sepasang sandal" dapat digunakan sebagai peralihan kepemilikan di

${ }^{68}$ Robert J. V. Hiebert et al., "Theological Dictionary of the Old Testament," Journal of Biblical Literature 119, no. 2 (2000): 381, https://doi.org/10.2307/3268510.

${ }_{69}$ Merril F. Unger and William White, Nelson's Expository Dictionary of the Old Testament (Nashville: Thomas Nelson Publishers, 1980).

70 Smith, Amos: A Commentary.

${ }^{71}$ Rathbone, "Capitalism, the Book of Amos and Adam Smith: An Analysis of Corruption." 
pengadilan (Rut. 4: 7-8). Namun menjual orang miskin dengan harga sepasang kasut merupakan sikap arogan yang tidak menghargai manusia. Dalam statusnya yang rendah orang miskin mudah dieksploitasi, diperjual-belikan bahkan dijadikan budak. Orang miskin semakin menderita karena tidak ada yang membelanya di pengadilan. Fakta kebenaran orang miskin dapat diputarbalikkan di pengadilan. ${ }^{72}$ Menurut Avi Shveka, para hakim melakukan korupsi di pengadilan dengan berusaha merampok para pencari keadilan sekalipun harganya hanya sepasang kasut. Bahkan mungkin terjadi pengambilalihan paksa tanah milik orang miskin untuk membayar hutangnya. ${ }^{73}$ Fakta ini memperlihatkan tindakan para kreditor yang lebih mementingkan nilai uang dari pada nilai diri seorang manusia. Sifat materialistik menjadikan nurani orang kaya tumpul, belas kasihnya terkekang sehingga merusak citra diri manusia. ${ }^{74}$ Lunturnya solidaritas kemanusiaan merupakan kejahatan sosiologis dan kejahatan teologis di hadapan Allah.

\section{Menginjak kepala orang lemah (6)}

Sikap solidaritas Israel merosot karena "menginjak-injak kepala orang lemah ke dalam debu tanah." Kata (saap) adalah tindakan sengaja menginjakinjak kepala orang lemah ke dalam tanah. Kata דלים (dalim) merupakan orang lemah yang sama sekali tidak berdaya. Menurut A. J. Fabry, dalim "orang lemah" adalah pekerja di ladang gandum atau kebun anggur yang hidupnya bergantung pada orang kaya. Ironisnya, orang lemah sering dieksploitasi tuan tanah karena hutang yang sangat kecil. Para pegawai raja turut menindas dan mengeksplotasi

72 G. Johannes Botterweck, "eviwon," Theological Dictionary of the Old Testament, vol. 2 (Grand Rapids: William B. Eerdmans Publishing Company, 1977).

${ }^{73}$ Avi Shveka, "'For a Pair of Shoes': A New Light on an Obscure Verse in Amos' Prophecy," Vetus Testamentum 62, no. 1 (2012): 95-114, https://doi.org/10.1163/156853311X580680.

${ }^{74}$ Andersen and Freedman, D, Amos. 
orang lemah. Demi meningkatkan pendapatan kerajaan, para pegawainya menaikkan pajak, melakukan korupsi dan penyuapan di pengadilan. ${ }^{75}$

Ketidakadilan juga terusik karena tuan tanah menyewakan tanahnya kepada orang miskin dengan harga yang mahal. Menurut Waard dan Smalley, prasa "mereka menginjak-injak kepala orang lemah" (7a) memperlihatkan seseorang yang tidak mendapat pertolongan dari debu tanah, atau menaruh debu tanah ke atas kepala orang lemah. Menaruh debu tanah di atas kepala juga tanda perkabungan, mengekspresikan kedukaan dan kerendahan hati. ${ }^{76}$ Menurut Smith, motivasi para tuan menginjak kepala orang lemah ke debu tanah bukanlah sekedar penindasan ekonomi melainkan penindasan secara fisik yang merusak harga diri manusia. Kesenangan orang kaya mengingini orang lemah tertindas dan teraniaya. Paul menganggap,"menginjak-injak kepala orang lemah ke debu tanah" adalah tindakan sengaja mendorong, melemparkan atau menghempaskan orang miskin ke jalanan. Tindakan keji dan tidak terpuji itu sengaja dilakukan menganggu orang miskin, merusak citra dirinya dan mencabut hak hidupnya. Mereka "sangat mengingini" setiap hal yang dimiliki oleh orang miskin, termasuk debu yang dilemparkan atas kepalanya. ${ }^{77}$ Penindasan seperti itu didorong sikap tamak dan loba, yang menguasai hidup dan harta milik orang miskin.

\section{Membelokkan jalan orang sengsara (7)}

Rusaknya solidaritas kemanusiaan Israel dengan "membelokkan jalan orang sengsara." Kata ענוים ('anawim) adalah "orang sengsara" yang posisinya lemah dan menderita. Ada kalanya kata 'anawim menunjuk orang yang rendah

\footnotetext{
${ }^{75}$ A. J. Fabry, Theological Dictionary of the Old Testament (Grand Rapids: William. B. Eerdmans Publishing Company, 1978).

76 Waard, Jan Smalley, and A, A Translator's Handbook on The Book of Amos.

77 Paul, Amos: A Commentary on The Book of Amos.
} 
hati. $^{78}$ Masyarakat marjinal hidupnya sengsara dan serba kekurangan. Kesengsaraan bertambah karena beban hutang sehingga memaksa orang tua menjual anak-anaknya menjadi budak. Bahkan menjual dirinya sendiri sebagai budak demi pembayaran hutang. ${ }^{79}$ Orang sengsara sering menjadi objek eksploitasi orang kaya atau penguasa, dengan cara yang tidak wajar mengambil hak hidup orang miskin. ${ }^{80}$ Sengaja memperdaya orang sengsara dalam kelemahannya adalah penindasan manusia. Perbuatan itu melawan hukum juga penegakan kebenaran dan keadilan.

\section{Mengeksploitasi perempuan (7)}

Dalam budaya patriakh laki-laki memiliki otoritas atas hidup perempuan. Karena itu perempuan rentan terhadap tindak kejahatan. Hal itu pun nampak dalam kritik Amos, "bapa dan anak pergi menjamah seorang perempuan muda." Penyebutan נערה (na'ara) menunjuk pada perempuan muda yang belum bersuami. $^{81}$ Eksploitasi perempuan memperlihatkan betapa memprihatinkannya kemerosotan moral di Israel. Kata לך (halak) dapat dipahami sebagai hubungan laki-laki dengan perempuan. Hukum kesucian menjamin relasi laki-laki dan perempuan, hamba perempuan bahkan perempuan asing (Bil. 22: 13; Ams. 1: 11).

Perbuatan yang dilakukan "bapa dan anak" itu sangat memalukan, sekaligus memperlihatkan kemerosotan moral keluarga. Keil Delitzsch menduga tindakan bapa dan anak itu dilakukan di tempat prostitusi sehingga keduanya melanggar kesucian pernikahan. Tindakan tidak senonoh terhadap perempuan

78 Unger and White, Nelson's Expository Dictionary of the Old Testament.

79 Claire Mathews McGinnis et al., "Theological Dictionary of the Old Testament," Journal of Biblical Literature, 2006, https://doi.org/10.1093/oxfordhb/9780199204540.003.0007.

80 Philip J. King, Amos, Hosea, Micah- An Archaeological Commentary (Philadelphia: The Westminster Press, 1989).

81 Smith, Amos: A Commentary. 
merupakan kebiasaan pergi ke tempat pelacuran. Bapa memberikan contoh yang tidak baik terhadap anaknya. Ada kemungkinan bapa dan anak sama-sama melakukan tindak kekerasan terhadap perempuan. ${ }^{82}$ Kekerasan domestik dapat terjadi di rumah melalui kekerasan seksual, pelecehan maupun pemerkosaan perempuan. ${ }^{83}$ Ada indikasi bahwa pelacur sudah menjadi profesi umum di kuilkuil suci. Hal itu dianggap sebagai pengabdian kepada dewa atau ilah. Namun S. M. Paul menganggap prasa itu bukanlah istilah kultus. ${ }^{84}$ Sebab dalam hukum kesucian ada larangan melakukan hubungan seksuil yang tidak senonoh dan implikasinya. ${ }^{85}$ Baginya, hubungan seksual bapa dan anak itu merupakan bentuk pengekploitasian yang dilakukan oleh majikan terhadap hamba atau perempuan lemah. Amos mencela ibadah kultus Israel yang tidak menjunjung supremasi moral. Pengeksploitasian perempuan melalui kejahatan seksual merupakan perampasan terhadap kemanusiaannya sekaligus pencemaran nama Tuhan. Perefleksian hukum kekudusan dan kesucian seksual harus diwujudkan dalam hidup sehari-hari.

\section{Denda dan beban hutang (8)}

Mezbah memiliki peran penting dalam upacara liturgis Israel. Bait Suci sebagai tempat kediaman Allah harus dijaga kesuciannya. Sayangnya, Israel menindas sesamanya, ${ }^{86}$ dengan "merebahkan diri di samping setiap mezbah di atas pakaian gadaian orang dan minum anggur orang yang kena denda (8a).”

82 Keil F dan Delitzsch, Commentary on the Old Testament: Minor Prophets.

83 Samuel and Kramer, "" Ripping Open Pregnant Women " in Light of an Assyrian Analogue Author ( $\mathrm{s}$ ): Mordechai Cogan Published by : American Oriental Society American Oriental Society Is Collaborating with JSTOR to Digitize , Preserve and Extend Access to Journal Of."

84 Paul, Amos: A Commentary on The Book of Amos.

85 Gernaida K.R. Pakpahan, Kristalisasi Keadilan Sosial Dalam Kitab Amos, ed. Frans Pantan and Abraham P Sitinjak, 1st ed. (Jaka: STT Bethel Indonesia, 2012). Kasih, 1996).

86 T. C. Mitchell, "Mezbah," in Ensiklopedi Alkitab Masa Kini (Jakarta, Yayasan Komunikasi Bina 
Orang yang kena denda umumnya orang miskin yang tidak mampu membayar hutang. Pakaian sebagai kebutuhan pokok agar tubuh manusia terlindung dapat digadaikan namun haruslah dikembalikan kepada si pemilik pada waktu petang. Namun keserakahan orang kaya tampak dalam pengambilan pakaian orang yang kena denda. $^{87}$

Tindakan Israel minum anggur orang yang kena denda di luar kemanusiaan. Anggur adalah lambang sukacita dalam kehidupan Israel. Solidaritas kemanusiaan pada waktu panen ditunjukkan petani anggur yang tidak membawa seluruh hasil panen agar orang miskin atau orang asing dapat menikmatinya. Menurut Paul, tindakan Israel minum anggur orang yang kena denda menjadikannya sebagai anggur beracun yang mematikan bagi yang meminumnya. Kegembiraan orang kaya seperti "racun yang mematikan" bagi orang miskin. ${ }^{88}$ Kejahatan lebih lagi sebab ada kemungkinan para imam terlibat dalam tindakan itu di "rumah Allah". Kekudusan mezbah Tuhan dikotori para imam dan orang kaya melalui penindasan. Kesetiaan ibadah Israel sesungguhnya terlihat dalam upacara liturgis dan belaskasihan kepada sesamanya. Kritik nabi Amos masih menggema kuat bagi gereja dan masyarakat.

Faktanya, praktik pelanggaran HAM mudah dijumpai dalam konteks masyarakat. Misalnya, masyarakat Papua belum seutuhnya menikmati kekayaan hasil buminya yang melimpah. Kesejahteraan penduduk terkait dengan ekonomi, pendidikan, kesehatan, infrastruktur belumlah merata. Kebebasan beribadah masih sulit bagi sebagian penduduk. Tampaknya, perjuangan panjang mewujudkan keadilan dan kesejahteraan merupakan tugas yang belum terselesaikan di Papua

${ }^{87}$ Keil F dan Delitzsch, Commentary on the Old Testament: Minor Prophets.

88 Paul, Amos: A Commentary on The Book of Amos. 
dan berbagai daerah lainnya. Banyaknya warna negara menjadi pekerja migran disebabkan sulitnya memperoleh pekerjaan di negeri sendiri. Dalam keadilan ekonomi, ada kesenjangan antara pekerja dan pengusaha, upah yang rendah, minimnya jaminan hari tua dan jaminan kesehatan, sulitnya menyampaikan pendapat, bahkan sering memperoleh intimidasi dan tekanan. Pekerja anak dan perempuan diperlakukan secara diskriminatif bahkan dieksploitasi tanpa rasa kemanusiaan.

Penegakan hukum di lembaga pengadilan sering menciderai rasa keadilan masyarakat. Praktik sogok dan suap sudah budaya yang mengakar kuat dalam sistem peradilan Indonesia. Hukum cenderung berpihak bagi pemilik modal sehingga sulit bagi kelompok lemah dan miskin untuk memperoleh keadilan hukum. Wajah peradilan Indonesia sering dinodai oleh para penegak hukum. Dengan demikian keadilan sosial merupakan tugas yang harus diupayakan secara terus menerus.

\section{KESIMPULAN}

Nubuat Amos menegakkan keadilan sosial melalui pembangunan solidaritas kemanusiaan relevan dengan tugas gereja dan negara. Negara menjamin hak hidup setiap warga negaranya. Gereja dipanggil agar aktif menyuarakan pembelaan terhadap hak asasi manusia melalui penegakan hukum, keadilan ekonomi, toleransi antar umat beragama, penolakan perdagangan manusia, penghargaan terhadap budaya dan kearifan lokal, dan kebebasan untuk bekerja dan berkarya, serta menolak segala bentuk tindakan diskriminatif, eksploitasi, intimidasi dan teror. Membangun solidaritas kemanusiaan dalam kasih Kristus dengan semangat persaudaraan. Setiap individu layak dihormati sebagai 
sesama, bebas berkarya dan bekerja dalam keamanan. Dengan demikian, penghargaan terhadap hak asasi manusia dapat terwujud dalam relasi harmonis bagi sesama dan dunia.

\section{KEPUSTAKAAN}

Aejmelaeus. "A Function and Interpretation of Ki in Biblical Hebrew." Journal Biblical Literature 105 (1986).

Allan, Kathryn, and Justyna A. Robinson. Current Methods in Historical Semantics. Current Methods in Historical Semantics, 2011. https://doi.org/10.1515/9783110252903.

Andersen, F.I, and N Freedman, D. Amos. New Haven, CT : Yale University Press. The Anchor Yale Bible 24A, 2008.

Andrerson, and Freedman. Amos: A New Translation with Introduction and Commentary. New York: The Anchor Bible, Doubleday, 1989.

Aronowitz, Alexis A. "Understanding Traficking in Human Beings: A Human Rights, Public Health, and Criminal Justice Issue." In International Crime and Justice, 2014. https://doi.org/10.1017/CCO9780511762116.018.

Barth, Christoph. Teologi Perjanjian Lama. Jakarta: BPK Gunung Mulia, 1993.

Becking, Bob. "The Betrayal of Edom: Remarks on a Claimed Tradition." HTS Teologiese Studies / Theological Studies 72, no. 4 (2016): 1-5. https://doi.org/10.4102/hts.v72i4.3286.

Blenkinsopp, J. A History of Prophecy in Israel. London: Darton Longmann and Todd, 1996.

Boland, BJ. Tafsiran Kitab Amos. Jakarta: BPK Gunung Mulia, 1993.

Botterweck, G. Johannes. "eviwon." Theological Dictionary of the Old Testament. Vol. 2. Grand Rapids: William B. Eerdmans Publishing Company, 1977.

Bright, John. History of Israel. London: SCM Press, 1960.

Durbin, Tom, and Jill St. George. "Human Traficking in Barbados: Achievements and Continuing Hurdles." Journal of Eastern Caribbean Studies, 2013.

Escobar, David A. "Amos \& Postmodernity: A Contemporary Critical \& Reflective Perspective on the Interdependency of Ethics \& Spirituality in the Latino-Hispanic American Reality." Journal of Business Ethics, 2011. 
https://doi.org/10.1007/s10551-011-0841-x.

European Union Agency for Fundamental Rights. Violence against Women : An EU-Wide Survey. Publications Office of the European Union, 2014.

Fabry, A. J. Theological Dictionary of the Old Testament. Grand Rapids: William. B. Eerdmans Publishing Company, 1978.

Fensham F. C. "Jahat, Kejahatan Dan Hukuman." In Ensiklopedia Alkitab Masa Kini. Yayasan Kasih Bina Kasih, 1994.

Hasel, Gerhard F. Understanding the Book of Amos: Basic Issues in Current Interpretation. Grand Rapids: Baker Book House, 1999.

Hayes, J. H. Old Testament Theology: Its History and Development. London: SCM Press, 1985.

Hiebert, Robert J. V., G. Johannes Botterweck, Helmer Ringgren, and Heinz-Josef Fabry. "Theological Dictionary of the Old Testament." Journal of Biblical Literature 119, no. 2 (2000): 381. https://doi.org/10.2307/3268510.

Hillyer, N. "Golan.” In Ensiklopedia Alkitab Masa Kini, 345. Yayasan Kasih Bina Kasih, 1994.

Hoad, J. W. L. “Janji.” In Ensiklopedi Alkitab Masa Kini. Yayasan Komunikasi Bina Kasih, 1994.

Honey, R. "Human Rights." In International Encyclopedia of Human Geography, 2009. https://doi.org/10.1016/B978-008044910-4.00785-9.

Human Rights Watch. "World Report 2020: Events of 2019." Human Rights Watch, 2019.

Keil F dan Delitzsch. Commentary on the Old Testament: Minor Prophets. Peabody: Hendrickson Publisher, 1989.

Kessler, R. "The Crimes of the Nations in Amos 1-2." Acta Theologica 2018 (2018): 206-20. https://doi.org/10.18820/23099089/actat.Sup26.12.

Kitchen, K. A. “Bani Amon.” Yayasan Komunikasi Bina Kasih, 1994.

_. "Gilead." In Ensiklopedi Alkitab Masa Kini. Yayasan Kasih Bina Komunikasi, 1994.

Klaussner, Carmen, and Carl Vogel. "A Diachronic Corpus for Literary Style Analysis." In LREC 2018 - 11th International Conference on Language Resources and Evaluation, 2019.

Kynes, Will. "God, Justice, and Society: An Overview.” Political Theology 14, no. 
https://doi.org/10.1179/1462317X13Z.00000000037.

Lawrence O. Richards. Expository Dictionary of Bible Words. Grand Rapids: Zondervan Publishing House, 1985.

Limburg, James. "Sevenfold Structures In The Book of Amos." Journal Biblical Literature 106/2 (1987): 217-22.

Linville, James R. "What Does ' It' Mean? Interpretation at the Point of No Return in Re-Reading ' It' This Paper Is a Synchronic Study of the Enigmatic Phrase ('I Will Not Cause ( Him / It ) to Return ') That Occurs in Each of the Eight Formally Linked Oracles against D," 2000, 400-425.

Loader, James Alfred. "Understanding of Failure and Failure of Understanding: Aspects of Failure in the Old Testament." HTS Teologiese Studies / Theological Studies 70, no. 1 (2014): 1-12. https://doi.org/10.4102/hts.v70i1.2657.

Mays, Luther. Amos: The Old Testament Library. Philadelphia: Westminster Press, 1969.

McGee J. Vernon. Tru The Bible: Proverbs to Maleachi. Nashville: Thomas Nelson Publisher, 1982.

McGinnis, Claire Mathews, Dale C. Allison, Walter Brueggemann, Tod Linafelt, T Desmond Alexander, David W Baker, James Barr, et al. "Theological Dictionary of the Old Testament." Journal of Biblical Literature, 2006. https://doi.org/10.1093/oxfordhb/9780199204540.003.0007.

Melugin, R. F. "Amos in Recent Research." Currents in Research: Biblical Studies 6 (1986).

Mendenhall, G. E. Law and Covenant in Israel and Ancient Near East. Pittsburgh: The Biblical Colloquium, 1955.

Mitchell T. C; A.R Millard. "Gaza." In Ensiklopedia Alkitab Masa Kini, 381. Yayasan Kasih Bina Kasih, 1994.

Mitchell, T. C. "Ekron.” In Ensiklopedi Alkitab Masa Kini. Yayasan Kasih Bina Kasih, 1994.

—. "Mezbah." In Ensiklopedi Alkitab Masa Kini. Jakarta, Yayasan Komunikasi Bina Kasih, 1996.

Moller, Karl. A Prophet in Debate: The Rhetoric of Persuasion in the Book of Amos. Journal for the Study of the Old Testament Supplement Series. Vol. 372, 2003.

Nogalski, James D., and John Barton. "Joel and Obadiah: A Commentary." Journal of the American Oriental Society, 2003. 
https://doi.org/10.2307/3217894.

Pakpahan, Gernaida K.R. Kristalisasi Keadilan Sosial Dalam Kitab Amos. Edited by Frans Pantan and Abraham P Sitinjak. 1st ed. Jaka: STT Bethel Indonesia, 2012.

Paul, S.M. Amos: A Commentary on The Book of Amos. Minneapolis: Fortress Press, 1991.

Philip J. King. Amos, Hosea, Micah- An Archaeological Commentary. Philadelphia: The Westminster Press, 1989.

Rad, Gerhard von. Theology of the Old Testament. New York: Harper and Row, 1960.

Rathbone, Mark. "Capitalism, the Book of Amos and Adam Smith: An Analysis of Corruption." HTS Teologiese Studies / Theological Studies 76, no. 4 (2020): 1-9. https://doi.org/10.4102/hts.v76i4.6194.

Rushdaony, Rousas John. Law and Society: Institut of Biblical Law. Vallecito: Ross House Books, 1982.

Samuel, To, and Noah Kramer. "" Ripping Open Pregnant Women " in Light of an Assyrian Analogue Author ( $\mathrm{s}$ ): Mordechai Cogan Published by: American Oriental Society American Oriental Society Is Collaborating with JSTOR to Digitize , Preserve and Extend Access to Journal Of" 103, no. 4 (2014): 755-57.

Shveka, Avi. "'For a Pair of Shoes': A New Light on an Obscure Verse in Amos' Prophecy." Vetus Testamentum 62, no. 1 (2012): 95-114. https://doi.org/10.1163/156853311X580680.

Smith, Gary V. Amos: A Commentary. Grand Rapids: Zondervan Publishing House, 1989.

Sunukjian, Donald R. "Amos." In The Bible Knowledge Commentary Old Testament, edited by John F Walvoord and Roy B Zuck. Victor Books, 1985.

Tebes, Juan Manuel. "Memories of Humiliation, Cultures of Resentment towards Edom and the Formation of Ancient Jewish National Identity." Nations $\begin{array}{lllll}\text { and Nationalism 25, no. } 1 & \text { (2019): } & 124-45 .\end{array}$ https://doi.org/10.1111/nana.12367.

Thompson, J. A.;, and A. R. Millard. "Moab." In Ensiklopedi Alkitab Masa Kini. Yayasan Komunikasi Bina Kasih, 1996.

Thompson, J. A. "Edom." In Ensiklopedi Alkitab Masa Kini. Yayasan Komunikasi Bina Kasih, 1994. 
Unger, Merril F., and William White. Nelson's Expository Dictionary of the Old Testament. Nashville: Thomas Nelson Publishers, 1980.

VanGemeren, William, and William. "Biblical Concept of Law." In Baker Encyclopedia of the Bible. Grand Rapids: Baker Book House, 1989.

Waard, De, W Jan Smalley, and Illiam A. A Translator's Handbook on The Book of Amos. New York, 1978.

Walvoord, John F, and Roy B Zuck. The Bible Knowledge Commentary. Voctor Books, 1985. https://doi.org/10.2307/3263215.

—. The Bible Knowledge Commentary Old Testament. Vol. 2, 1983.

Wight Fred H. Manners and Customs of Bible Land. Chicago: Moody Press, 1980.

Wiseman, D. J. “Asdod.” In Ensiklopedi Alkitab Masa Kini. Yayasan Kasih Bina Kasih, 1994.

—. "Askelon." In Ensiklopedi Alkitab Masa Kini. Yayasan Kasih Bina Kasih, 1994.

Wolff, Hans Walter. Joel and Amos. Philadelphia: Fortress Press, 1997. 